\title{
Fundamental Analysis, Stock Returns and High B/M Companies
}

\author{
G.P. Kourtis ${ }^{1}$, E.P. Kourtis ${ }^{2}$, M.P. Kourtis ${ }^{3}$, P.G. Curtis ${ }^{4}$
}

\begin{abstract}
:
In this paper we initially estimate the financial performance of high BM companies based on the analysis of profitability, liquidity-leverage and operating efficiency ratios.

The performance of the specific group as a whole, was found to be quite poor and that is why it is reflected in a high BM ratio score for the companies involved.

The research then showed that a portfolio of the best performing high BM companies, chosen through the F-score mechanism, exhibits a statistically significant higher mean of marketadjusted as well as raw returns, compared to any other type of classification of the companies of the category.
\end{abstract}

The research was conducted for the period 2010-2015 and applied to companies listed in the North America Stock Exchange Markets.

\footnotetext{
${ }^{1}$ MSc Accounting and Control, Erasmus University, Rotterdam, giorgoskourtis90@gmail.com

${ }^{2}$ School of Civil Engineering NTUA

${ }^{3}$ School of Electrical and Computer Engineering NTUA

${ }^{4}$ Ass. Professor TEI Stereas Elladas, pgcurtis@yahoo.gr
} 


\section{Introduction}

Ball and Brown (1968) were pioneers in examining whether the accounting data and more specifically the change of net income, matters in explaining the changes in stock prices in the capital markets. They used the CAPM model as the mechanism to associate the accounting numbers to stock returns. Ball and Brown investigated the relationship between unexpected earnings and abnormal rates of return for 261 stocks of companies listed at the New York Stock Exchange, during the period 1957 to 1965 . They argued that the evaluation of accounting income requires to examine the "content and the timing" of the income and "its usefulness could be impaired by deficiencies in either". They showed, contrary to what up to then was the prevalent belief, that the movements of stocks' returns and the financial statement information are associated. In addition, they stated that earnings contain a great deal of information reflected in stocks returns as well as and highlighted the predictive power of earnings in explaining future abnormal stock returns.

According to Kothari (2001), the investment strategy that relies on financial statement analysis data, forms a discrete field of research in accounting, the socalled capital markets research originated in the landmark work of Ball and Brown. Dechow et al. (2014) consider that their work is based on three assumptions about how investors use earnings to determine stock prices (Thalassinos and Politis, 2011; Thalassinos and Thalassinos, 2006; Thalassinos et al., 2015).

These assumptions are the following: a) markets are efficient, b) higher earnings are linked to higher firm value and c) their model reflects investors' earnings expectations.

Fama (1965), who previously conceived a framework of stock prices prediction based on pertinent information, facilitated this development in capital markets research in accounting. He argued that prices contain all available information and follow a random walk. It is also known, that Fama (1965) is identified with the EMH.

Beaver (1968), in the same year with the study of Ball and Brown (1968), focused on the information relevance of net income at the moment of the announcement of financial statements. He searched for empirical evidence based on trading volume and the volatility of earnings that ensue an earnings announcement. Beaver concluded that net income figures were relevant since the announcement of the financial results, affected the volume and the price of stocks involved in the week after the announcement. In addition Beaver (1968) argued, that the link between earnings and stock prices is the assumption that the current earnings provide information to predict future earnings.

To test the validity of the allegations that fundamentals and financial statement analysis are valuable in explaining stock price changes, we explore the case of high 
BM companies. The researchers have identified the poor fundamentals of high BM companies. The financial underperformance of these companies is reflected in their lower market value compared to their book one. Fama and French (1992) argued that high Book to Market (where BM>1) companies exhibit rather financially distressed fundamentals and so their stocks can be characterized as riskier, compared to the ones of other companies that trade in the same market. As a result, the higher returns (compared to the growth stocks' ones ) that these companies earn in the market, are justified as a kind of remuneration for the additional risk they bear. They specify that the signs of financial distress are the higher leverage, the lower return on equity, the lower liquidity, the earnings fluctuations etc., (Fama and French, 1995). Lakonishok et al. (1994) believe that as a result of the unsatisfactory performance of those companies, create pessimistic expectations, don't draw enough investors' attention and exhibit lower demand for their stocks. Consequently they allege, whenever their financial performance improves it is understandably translated into higher market value changes.

The F-score screening mechanism (introduced by Piotroski in 2000), encourages the use of the fundamental analysis, which exploits financial statements data. The model implicitly stresses the need for dependable data and prudent financial reporting policies that finally compensate all stakeholders and the economy. Piotroski (2000) recognizes problems regarding the quality of financial reporting. That is why the Fscore model, is embedding in the analysis of accruals and cash flows measures when profitability is examined. Two of the four profitability ratios, that are included in the F-score, refer to earnings that are based on the accruals and the rest two refer to the cash flows and their amount in comparison to accruals. By doing so Piotroski takes care of the problem of the quality of the data and therefore he bolsters the effectiveness of the F-score as a tool of assessment of the real current financial performance of companies, that can also be used to evaluate the future earnings and the change in the returns of stocks involved. The model finally contributes to more efficient allocation of resources in the economy, by directing resources to companies that expose more sound fundamentals (Hanias et al., 2007; Thalassinos et al., 2012).

\section{Methodology and Data}

The data in this paper is retrieved using Wharton Research Data Services (WRDS) database and more specifically from Compustat North America -Fundamentals Annual. The final sample was constructed after taking into consideration specific criteria. The data of interest in order to calculate the variables involved in the paper, presented in the following Table 1:

Table 1: Data retrieved for the period 2010-2015

\begin{tabular}{l}
\hline 1. Current assets \\
2. Total assets \\
3. Total shares \\
4. Long-Term Debt
\end{tabular}




\begin{tabular}{|l|}
\hline 5. Gross Profit \\
6. Current Liabilities \\
7. Net Profit \\
8. Cash flows from operations \\
9. Sales \\
10. Equity \\
11. Market value of equity \\
12.Year-end closing stock price \\
13.Year-end closing market index (NASDAQ, \\
NYSE, S\&P/TSX) \\
\hline
\end{tabular}

The sample consists of listed companies operating in North America during the period 2010-2015. The initial sample consisted of 51.994 observations, in which were involved all listed companies in North America, excluding the ones operating in the financial services sector (Table 2).

Table 2: Sample selection stages

\begin{tabular}{|c|c|c|}
\hline \multicolumn{3}{|l|}{ Sample selection } \\
\hline & Observations & Companies \\
\hline $\begin{array}{l}\text { Listed companies in North America excluding } \\
\text { those providing financial services }\end{array}$ & 51.944 & 12.986 \\
\hline $\begin{array}{l}\text { Delete companies that do not have available } \\
\text { data in the period 2011-2014 }\end{array}$ & 26.940 & 6.735 \\
\hline $\begin{array}{l}\text { Delete companies that do not have 12-month } \\
\text { year end fiscal years }\end{array}$ & 14.664 & 3.666 \\
\hline $\begin{array}{l}\text { Keep companies with Book-to-Market ratio } \\
\text { above one }\end{array}$ & 2.808 & 702 \\
\hline Keep companies with revenue above zero & 2.252 & 563 \\
\hline $\begin{array}{l}\text { Keep companies that have available data for } \\
\text { all years } 2010-2015\end{array}$ & 456 & 114 \\
\hline Delete companies listed in OTC markets & 284 & 71 \\
\hline
\end{tabular}

Source: Wharton Research Data Services (WRDS): Compustat North America Fundamentals Annual.

Nevertheless, during the data analysis, and especially after the calculation of the market-adjusted stocks returns (MA_RET) and raw returns (RAW_RET) for each company at the end of each year (during the period 2011-2014), it was observed that some companies exhibit stock returns considerably higher than $30 \%$ of the respective market index. According to Field (2009), the outliers can cause biased 
models because they influence the values of the estimated regression coefficients. It is known that, outliers' repercussions especially in the samples that are not large enough may cause model misspecification biased parameter estimation, and therefore incorrect analysis results. For that reason, companies achieved one-year ahead change of market-adjusted returns (MA_RET) 30\% or more during the period 2010-2015 were excluded. Therefore, the final sample consists of 71 companies and their observations differ from year to year.

\section{Model and Variables}

The variable MAR_RET is defined as the one-year ahead change of the stocks' market-adjusted return, for company $i$, from year $t$ to the next $t+1$. MA_RET variable is calculated as follows:

$M A_{-} R E T_{i t}=\left(\frac{P_{i t+1}}{P_{i t}}-1\right)-\left(\frac{I N D E X_{t+1}}{I N D E X_{t}}-1\right)$

$P_{t=} \quad$ Stock price in the year-end $t$ and

$I N D E X_{t}=\quad$ Market index in the year-end $\mathrm{t}$

Respectively, for the study's purposes, we define the variable RAW_RET as the one-year ahead change only in the stock return (without adjusting for the impact of the respective Index as it is in the calculation of MA_RET) for company i, from year $\mathrm{t}$ to the next $\mathrm{t}+1$. RAW_RET variable is calculated as follows:

$R A W_{-} R E T_{i t}=\left(\frac{P_{i t+1}}{P_{i t}}-1\right)$

We calculate the variables MAR_RET and RAW_RET as well as all the ratios included in the F-score of Piotroski (2000).

\subsection{F_SCORE variable}

According to prior researches and specifically those of Piotroski (2000), Krauss et al. (2015), Fama and French (1995), Chen and Zhang (1998), Harris and Raviv (1990), Myers and Majluf (1984), Miller and Rock (1985) three aspects of financial performance fundamentals exist that can differentiate high from low performance companies. Those are: (i) profitability, (ii) leverage-liquidity and (iii) operating efficiency. Profitability reflects the ability of a company to use its assets in order to generate profits measured on accruals and/or cash flows from operations (CFO). The liquidity ratios measure the ability of a company to meet its short-term obligations based on current assets and cash. In addition the leverage ratios measure the proportion of debt to equity that implies the ability of a company to finance its 
operations. Operating efficiency is comprised of two financial ratios. The first one is the so-called assets turnover ratio and portrays of how efficiently a company transforms the invested capital into sales. Sales value is attributed to either higher quality-differentiation or to lower cost and/or focus, depending on the company's generic strategies in the market according to Porter(1980). The other ratio refers to the improvement of the gross profit margin of the last year compared to the previous one and it indicates better performance mainly in restraining costs. By examining, each of the nine ratios each one individually leads to:

(i) Profitability ratios:

1. Positive ROA in the current year $t$ gets a score 1 , otherwise 0 .

2. Positive operating cash flow in the current year $t$ gets a score 1 , otherwise 0 .

3. Higher ROA in the current year t compared to ROA in previous year $\mathrm{t}-1$ scores 1 , otherwise 0 .

4. CFO greater than ROA scores 1 , otherwise 0 .

(ii) Leverage/liquidity ratios:

5 . Lower value of long-term debt in the current year t compared to previous year $\mathrm{t}-1$ scores 1 , otherwise 0 .

6. Higher current ratio (current assets divided by current liabilities) in the current year $\mathrm{t}$ compared to previous year $\mathrm{t}-1$ scores 1 , otherwise 0 .

7. New shares issued in the current year t scores 0 , otherwise 1.

(iii) Operating efficiency ratios:

8. A higher gross margin this year than in previous year $\mathrm{t}-1$ scores 1 , otherwise 0

9. A higher asset turnover ratio (total sales divided by total assets) in current year $t$ than the previous year $\mathrm{t}-1$ scores 1 , otherwise 0 .

Therefore, the nine financial ratios and the respective dummies were constructed for F_SCORE and

$F_{-} S C O R E=F_{-} R O A+F_{-} \triangle R O A+F_{-} C F O+F_{-} A C C R U A L+F_{-} \triangle M A R G I N+F_{-} \triangle T U R N$

$+F_{-} \Delta L E V E R+F_{-} \triangle L I Q U I D+E Q_{-} O F F E R$

According to Piotroski (2000) investing in companies that exhibit a greater total sum, means that the corresponding ratios improved in the current year compared to the previous one and therefore their financial performance is bolstered.

In the sample of companies examined, the maximum F-score reported was nine (9) and the lowest one (1). We considered as high financial performing companies the ones that receive F-score equals from seven to nine (7-9), the medium financial performing companies get F-score from four to six (4-6) and the rest that exhibit Fscore from one to three (1-3) were characterized as low financial performing companies. 


\section{Financial Statement Analysis}

High BM companies, financial ratios and F-score:

In order to measure the financial performance of the high BM companies included in the final sample, we performed financial statement analysis based on the ratios used by Piotroski (2000). The following table gives a quite detail-overall picture of the financial performance. It is worth noting, that EQ_OFFER signal is not mentioned, since it takes only the binary values 1 and 0 . The market value, total assets and the $\mathrm{BM}$ indices, were also calculated and incorporated. The descriptive statistics of the companies are shown in Table 3.

Table 3: Financial Characteristics of high BM companies

\begin{tabular}{|l|l|l|l|l|}
\hline Variable & Mean & Median & Standard Deviation & $\begin{array}{l}\text { Proportion with } \\
\text { positive signal }\end{array}$ \\
\hline MVE & 532.758 & 102.485 & 1293.140 & \\
\hline Assets & 2108.820 & 366.838 & 5221.749 & \\
\hline BM & 2.335 & 1.745 & 1.627 & 0.539 \\
\hline ROA & -0.015 & 0.004 & 0.120 & 0.417 \\
\hline$\triangle$ ROA & -0.009 & -0.006 & 0.150 & 0.422 \\
\hline$\triangle$ MARGIN & 0.187 & 0.155 & 0.134 & 0.843 \\
\hline CFO & 0.050 & 0.045 & 0.057 & 0.487 \\
\hline$\triangle$ LIQUID & 0.081 & -0.002 & 2.143 & 0.400 \\
\hline$\triangle$ LEVER & 0.001 & -0.004 & 0.067 & 0.483 \\
\hline$\triangle$ TURN & -0.009 & 0.000 & 0.197 & 0.143 \\
\hline ACCRUAL & -0.065 & -0.048 & 0.118 & $N 00 t h$ America \\
\hline
\end{tabular}

Source: Wharton Research Data Services (WRDS): Compustat North America Fundamentals Annual

The sample is not homogeneous. Asymmetry and extreme values characterize most of the financial variables presented in the table. As a result the mean and the median differ considerably. It is known that outliers affect predominately the mean, than the median. It is particularly obvious in the cases of the variables MVE and Assets. The means of ROA and $\triangle$ ROA are negative, as well as the corresponding mean of ACCRUAL and $\triangle T U R N$ ratios, indicating how much distressed the high BM companies of my sample are. Given that ROA and $\triangle \mathrm{ROA}$ are considered to be direct profitability measures, their values depict the dire situation that the companies are in, with respect to that dimension. This observation is invigorated further, by taking into consideration the ratio $\triangle \mathrm{TURN}$ (that measures efficiency), which is also an indirect 
measure of ROA (since ROA = Net profit margin multiplied by sales turnover). TURN ratio is calculated dividing sales by the assets employed. Given that its mean is also negative, it constitutes an additional factor that is aggravating further the poor performance of the high BM stocks of my sample. These findings are in line with the previous research of Fama and French (1992) regarding high BM companies and the general perception regarding the financial performance of this category of companies.

ACCRUAL (defined as ROA minus CFO scaled by total assets), it is the only negative financial ratio (only $14.3 \%$ of the companies' observations involved in the period under consideration is positive), and that does not represent a drawback. The variable $\mathrm{CFO}$ is positive in $84.3 \%$ of the sample. CFO at the same time is considered the least amenable to manipulation item by the management, compared to accrual accounting earnings. A positive $\mathrm{CFO}$ greater than accruals, is considered a measure of quality of earnings. It was found that during the crisis " the change in most determinants of earnings quality, favors higher earnings quality" (Kousenidis et al., 2013). All these observations justify the negative sign of ACCRUAL, meaning that $\mathrm{CFO}$ are greater than earnings. The fact that profitability of the high BM companies is low or even negative in the sample, indicates the poor financial performance of the companies involved. The latter, represents a factor contributing to a low value of the company in the market, compared to the corresponding book one, resulting finally into high BM ratio.

Raw and market-adjusted returns:

We saw that he high BM companies exhibit poor financial performance that, is reflected in their low market value. Those companies exhibit quite often erratic behavior with respect to their stock returns. We then filter extreme returns in order to purge the sample of the outliers and construct the return of investment strategy for those companies as shown in Table 4.

Table 4: One-year ahead returns of an investment in high BM companies

\begin{tabular}{|l|l|l|l|l|l|l|l|}
\hline \multirow{2}{*}{ Returns } & \multirow{2}{*}{ Mean } & \multicolumn{3}{|l|}{ Percentile } & \multirow{2}{*}{ Percent Positive } \\
\cline { 3 - 7 } & & 10th & 25th & Median & 75th & 90th & \\
\hline RAW_RET & -0.093 & -0.509 & -0.275 & -0.063 & 0.125 & 0.254 & 0.396 \\
\hline MA_RET & -0.200 & -0.577 & -0.388 & -0.193 & 0.028 & 0.147 & 0.287 \\
\hline
\end{tabular}

Source: Wharton Research Data Services (WRDS): Compustat North America Fundamentals Annual.

To examine the hypothesis that the market adjusted returns (MA_RET) are normally distributed with mean value -0.20 and standard deviation 0.28 , the normality Shapiro - Wilks (S-W) and Kolmogorov-Smirnov (K-S) tests are used. Since the sample size 
is large enough the $\mathrm{S}-\mathrm{W}$ test is not biased. Furthermore, since the extreme values have been removed from the sample, the K-S test can be also used as well. According to the results of the $\mathrm{S}-\mathrm{W}(\mathrm{W}=0.990$, $\mathrm{p}$ value $=0.11>0.05)$ and $\mathrm{K}-\mathrm{S}$ tests $(\mathrm{p}$ value $=0.41>0.05$ ). Thus we cannot reject the hypothesis that the distribution is normal. Taking into account raw returns (RAW_RET) and trying to examine the same hypothesis (normal destitution with mean -0.09 and standard deviation=0.30), the result of the $\mathrm{S}-\mathrm{W}(\mathrm{W}=0.992, \mathrm{p}$ value $=0.24>0.05)$ and $\mathrm{K}-\mathrm{S}$ (p value 0.316 $>0.05$ ) tests, lead us not to reject the hypothesis.

Table 4 presents the one-year ahead change of stocks' market-adjusted returns (MA_RET) and raw returns (RAW_RET) for the entire sample with high BM companies' observations, along with the percentage of negative (losses are more than profits) and positive returns over the respective investment horizon. According to Piotroski (2000) any investment strategy that contains (or even eliminate) the left tail (negative) of return distribution, will ameliorate the average return of the portfolio. According to the table, only $28.7 \%$ and $39.6 \%$ of the market-adjusted stock returns respectively raw returns are positive. This result underscores the low performance of the high BM companies for the period under consideration. The means are $-20 \%$ and $-9.3 \%$ for the market-adjusted and raw returns respectively.

These results show that the mean of the entire sample of the companies' observations with high BM, achieve negative raw returns and even lower marketadjusted returns. The latter reveals that the returns of the stocks of high BM companies are lower compared to the average of the stocks' returns of the rest companies that trade in the respective Market Index. The financial performance of high BM-companies measured by the nine ratios included in the F-score and their unsatisfactory one-year ahead change of market-adjusted returns achieved, reflect their underperformance compared to the rest of the market.

Financial performance of high BM-companies' observations and sample partition based on F-score:

The sample of companies examined for the entire period is then divided into three groups according to the F-score. The first group includes 34 companies' observations $(\mathrm{N}=34)$ that achieve $\mathrm{F}$-score values of $0-3$. The second group comprises 144 companies' observations $(\mathrm{N}=144)$ that attain F-score values from four to six (4$6)$. The last group contains 52 companies' observations $(\mathrm{N}=52)$ that achieve F-score values from seven to nine (7-9). The three groups are defined as low, medium and high performing respectively based on their F-score value. Then, we mainly focus on the comparison of the returns (MA_RET and RAW_RET) between high and low groups, as well as between high and the entire sample of observations.

The financial performance of each of the three groups with respect to the nine financial ratios, that are included in the F-score, is presented in the following Table 5: 
Table 5: Number of observations by variable and total F-score groups

\begin{tabular}{|c|c|c|c|c|c|c|c|}
\hline \multirow{3}{*}{ Variable } & \multirow{3}{*}{ Values } & \multicolumn{6}{|c|}{ Groups By F-score } \\
\hline & & \multicolumn{2}{|c|}{ Low } & \multicolumn{2}{|c|}{ Medium } & \multicolumn{2}{|c|}{ High } \\
\hline & & $\mathbf{N}$ & $\%$ & $\mathbf{N}$ & $\%$ & $\mathbf{N}$ & $\%$ \\
\hline \multirow{2}{*}{ F_ROA } & 0 & 22 & $64.7 \%$ & 70 & $48.6 \%$ & 12 & $23.1 \%$ \\
\hline & 1 & 12 & $35.3 \%$ & 74 & $51.4 \%$ & 40 & $76.9 \%$ \\
\hline \multirow{2}{*}{ F_CFO } & 0 & 15 & $44.1 \%$ & 21 & $14.6 \%$ & 0 & $0.0 \%$ \\
\hline & 1 & 19 & $55.9 \%$ & 123 & $85.4 \%$ & 52 & $100.0 \%$ \\
\hline \multirow{2}{*}{$\mathrm{F} \_\Delta \mathrm{ROA}$} & 0 & 30 & $88.2 \%$ & 92 & $63.9 \%$ & 12 & $23.1 \%$ \\
\hline & 1 & 4 & $11.8 \%$ & 52 & $36.1 \%$ & 40 & $76.9 \%$ \\
\hline \multirow{2}{*}{ F_ACCRUAL } & 0 & 11 & $32.4 \%$ & 21 & $14.6 \%$ & 1 & $1.9 \%$ \\
\hline & 1 & 23 & $67.6 \%$ & 123 & $85.4 \%$ & 51 & $98.1 \%$ \\
\hline \multirow{2}{*}{ F_ALEVER } & 0 & 30 & $88.2 \%$ & 70 & $48.6 \%$ & 16 & $30.8 \%$ \\
\hline & 1 & 4 & $11.8 \%$ & 74 & $51.4 \%$ & 36 & $69.2 \%$ \\
\hline \multirow{2}{*}{ F_ALIQUID } & 0 & 21 & $61.8 \%$ & 80 & $55.6 \%$ & 16 & $30.8 \%$ \\
\hline & 1 & 13 & $38.2 \%$ & 64 & $44.4 \%$ & 36 & $69.2 \%$ \\
\hline \multirow{2}{*}{ EQ_OFFER } & 0 & 27 & $79.4 \%$ & 76 & $52.8 \%$ & 19 & $36.5 \%$ \\
\hline & 1 & 7 & $20.6 \%$ & 68 & $47.2 \%$ & 33 & $63.5 \%$ \\
\hline \multirow{2}{*}{ F_MARGIN } & 0 & 34 & $100.0 \%$ & 91 & $63.2 \%$ & 3 & $5.8 \%$ \\
\hline & 1 & 0 & $0.0 \%$ & 53 & $36.8 \%$ & 49 & $94.2 \%$ \\
\hline \multirow{2}{*}{ F_ATURN } & 0 & 27 & $79.4 \%$ & 74 & $51.4 \%$ & 7 & $13.5 \%$ \\
\hline & 1 & 7 & $20.6 \%$ & 70 & $48.6 \%$ & 45 & $86.5 \%$ \\
\hline
\end{tabular}

Source: Wharton Research Data Services (WRDS): Compustat North America Fundamentals Annual.

Table 5 is based on the whole sample of 230 companies- observations for the period 2010-2015. As far as the 52 high performing companies' observations are concerned, the best achievement is realized for the ratios F_CFO, F_ACCRUAL, and F_MARGIN. While at the same time, the relatively worst achievement is shown in the ratio EQ_OFFER, (i.e. companies issue new shares and therefore it causes dilution of management control) and $F \_\triangle L E V E R$ indicating no change in long-term debt. The results in the most numerous medium category seem to be rather inconclusive and do not represent a group that my research (following Piotroski) is focused upon. It is worth noticing that a company in order to be able to be classified as high performing, must excel in two (at least) of the three dimensions of financial performance or in seven out of the nine ratios. Piotroski who uses a greater sample, defines as high performing companies which exhibit F-score eight (8) or (9).

Therefore, the high performing companies excel in all three financial ratios categories, as the profitability ratios are four, the leverage-liquidity are three and the operating efficiency are two. Taking into consideration that high performing companies must exhibit F-score eight (8) in total at least, it is required to receive at least the favorable value of one (1) for all the categories ratios. To that end, the high performance is the result of the fulfillment of a multilevel index. It also reveals that financial excellence is a difficult, complex challenging and demanding task, which 
encompasses many facets of performance. To that extend it is indicative that $\mathrm{Ou}$ and Penman (1989), Lev and Thiagarajan (1993), Abarbanell and Bushee (1998) before Piotroski (2000) used a number of ratios combined into an index, in order to forecast future company performance. In addition, the Z-score of Altman (1968) includes a weighted average of five ratios that measure profitability, liquidity, debt/equity and efficiency in order to assess the probability that the company will be solvent (or not) in the near future.

\section{Market-adjusted returns, raw returns and financial performance:}

In this section, the focus is on the association of the one-year ahead change of market-adjusted returns as well as raw returns, with each of the nine financial ratios individually and the aggregate measure of F-score.

Table 6: MA_RET, RAW_RET and F-score correlations

\begin{tabular}{|c|c|c|c|c|c|c|c|c|c|c|c|c|}
\hline Variable & $\begin{array}{l}\text { RAW_- } \\
\text { RET }\end{array}$ & $\begin{array}{l}\text { MA } \\
\text { RET }\end{array}$ & $\begin{array}{l}\text { F_R } \\
\mathbf{O A}\end{array}$ & $\begin{array}{l}\text { F_C } \\
\text { FO }\end{array}$ & $\begin{array}{l}\mathrm{F}_{\overline{\mathrm{R} O}} \\
\mathrm{~A} \mathrm{O}\end{array}$ & $\begin{array}{l}\text { F }_{-} \\
\text {ACCR } \\
\text { UAL }\end{array}$ & $\begin{array}{l}\text { F_a } \\
\mathbf{L E V} \\
\text { ER }\end{array}$ & $\begin{array}{l}\text { F_a } \\
\text { LIQ } \\
\text { UID }\end{array}$ & $\begin{array}{l}\text { EQ_ } \\
\text { OFF } \\
\text { ER }\end{array}$ & $\begin{array}{l}\text { F_M } \\
\text { AR } \\
\text { GIN }\end{array}$ & $\begin{array}{l}\text { F_a } \\
\text { TUR } \\
\mathbf{N}\end{array}$ & $\begin{array}{l}\text { F_S } \\
\text { CO } \\
\text { RE }\end{array}$ \\
\hline $\begin{array}{l}\text { RAW } \\
\text { RET }\end{array}$ & 1.00 & 0.91 & 0.13 & 0.01 & 0.01 & -0.05 & 0.08 & 0.03 & 0.09 & 0.04 & 0.10 & 0.14 \\
\hline $\begin{array}{l}\text { MA } \\
\text { RET }\end{array}$ & & 1.00 & 0.08 & 0.04 & -0.03 & -0.02 & 0.08 & 0.02 & 0.11 & 0.08 & 0.15 & 0.16 \\
\hline F_ROA & & & 1.00 & 0.16 & 0.29 & -0.30 & 0.13 & 0.00 & -0.21 & -0.03 & -0.19 & 0.28 \\
\hline F_CFO & & & & 1.00 & 0.10 & 0.37 & 0.14 & -0.01 & -0.10 & 0.05 & -0.05 & 0.38 \\
\hline$F_{-} \Delta R O A$ & & & & & 1.00 & -0.08 & 0.02 & 0.05 & 0.02 & 0.22 & -0.02 & 0.51 \\
\hline $\begin{array}{l}\text { F_ACC } \\
\text { RUAL }\end{array}$ & & & & & & 1.00 & 0.11 & -0.04 & 0.06 & 0.14 & 0.06 & 0.26 \\
\hline $\begin{array}{l}\text { F_ALEV } \\
\text { ER }\end{array}$ & & & & & & & 1.00 & -0.24 & -0.04 & 0.01 & 0.04 & 0.33 \\
\hline $\begin{array}{l}\text { F_aLIQ } \\
\text { UID }\end{array}$ & & & & & & & & 1.00 & 0.09 & 0.07 & -0.10 & 0.26 \\
\hline $\begin{array}{l}\text { EQ_OFF } \\
\text { ER }\end{array}$ & & & & & & & & & 1.00 & 0.12 & 0.08 & 0.30 \\
\hline $\begin{array}{l}\text { F_MAR } \\
\text { GIN }\end{array}$ & & & & & & & & & & 1.00 & 0.54 & 0.65 \\
\hline $\begin{array}{l}\text { F } \\
\Delta \text { TURN }\end{array}$ & & & & & & & & & & & 1.00 & 0.42 \\
\hline $\begin{array}{l}\text { F_SCOR } \\
\text { E }\end{array}$ & & & & & & & & & & & & 1.00 \\
\hline
\end{tabular}

Source: Wharton Research Data Services (WRDS): Compustat North America Fundamentals Annual.

Table 6 is the correlation matrix of the two return variables, market adjusted (MA_RET) and raw (RAW_ET), nine financial ratios, rated 1 or 0 and the F_SCORE which is the sum of the nine indices. The purpose is to examine whether the F-score is more correlated to return variables than the factors that create it. As most variables take only two values ( 0 or 1 , binary data), Spearman correlation measure was affected. From the results it is observed that a F_SCORE has a nontrivial positive correlation with both RAW_RET and MA_RET, 0.141 and 0.156 $($ sig $=0.032)$ respectively in line with Piotroski's findings (correlation to MA_RET = 
0.121 and RAW_RE=0.124) and comparable to them. At the same time, the three strongest individual explanatory variables of MA_RET are F_DTURN, F_ROA and F_MARGIN (correlation of 0.152 (sig. 0.021), 0.078 (sig.0.240) and 0.076 (sig 0.252) respectively. Furthermore, the ACCRUAL variable shows a negative correlation -0.020 with respect to MA_RET (though not statistically significant, sig=0.761. Finally, MA_RET shows a greater correlation $(0.156$, sig $=0.032)$ than RAW_RET $(0.141$, sig=0.032) with respect to the F-score and both of them are statistically significant at the 0.05 significance level.

Market-adjusted returns (MA_RET) of an investment strategy of high performing portfolio screened by the F-score:

We then examine the possibility to lose useful information by transforming the financial variables-ratios in to their binary form of 0 and 1 , in order to follow Piotroski's method. Therefore, we recalculate the results using binary signs this time.

Table 7: Investment strategy through the screening mechanism of F-score using binary signs

\begin{tabular}{|c|c|c|c|c|c|c|c|c|}
\hline MA_RET & $\begin{array}{l}\text { Mean of } \\
\text { MA_RET }\end{array}$ & $5 \%$ & $25 \%$ & $50 \%$ & $75 \%$ & $95 \%$ & $\mathbf{N}$ & $\begin{array}{l}\text { n\% } \\
\text { positive }\end{array}$ \\
\hline F_SCORE $=1$ & -0.192 & -0.213 & -0.213 & -0.192 & -0.170 & -0.170 & 2 & $0.00 \%$ \\
\hline F_SCORE $=2$ & -0.271 & -0.674 & -0.420 & -0.297 & -0.121 & 0.160 & 9 & $0.11 \%$ \\
\hline F_SCORE $=3$ & -0.320 & -0.802 & -0.610 & -0.264 & -0.162 & 0.125 & 23 & $0.17 \%$ \\
\hline F_SCORE $=4$ & -0.206 & -0.614 & -0.481 & -0.176 & 0.009 & 0.229 & 55 & $0.25 \%$ \\
\hline F_SCORE $=5$ & -0.194 & -0.825 & -0.354 & -0.207 & 0.067 & 0.177 & 53 & $0.40 \%$ \\
\hline F_SCORE $=6$ & -0.210 & -0.906 & -0.366 & -0.213 & -0.027 & 0.143 & 36 & $0.22 \%$ \\
\hline F_SCORE $=7$ & -0.118 & -0.528 & -0.254 & -0.110 & 0.082 & 0.275 & 36 & $0.36 \%$ \\
\hline F_SCORE $=8$ & -0.163 & -0.772 & -0.324 & -0.120 & 0.020 & 0.260 & 14 & $0.29 \%$ \\
\hline F_SCORE $=9$ & -0.077 & -0.250 & -0.250 & -0.077 & 0.096 & 0.096 & 2 & $0.50 \%$ \\
\hline All Firms & -0.200 & -0.677 & -0.387 & -0.193 & 0.025 & 0.207 & 230 & $0.29 \%$ \\
\hline Low & -0.300 & -0.802 & -0.525 & -0.252 & -0.162 & 0.160 & 34 & $0.15 \%$ \\
\hline Medium & -0.203 & -0.677 & -0.388 & -0.191 & 0.038 & 0.177 & 144 & $0.30 \%$ \\
\hline High & -0.129 & -0.538 & -0.281 & -0.112 & 0.059 & 0.271 & 52 & $0.35 \%$ \\
\hline High-All & 0.072 & 0.139 & 0.106 & 0.081 & 0.034 & 0.064 & & \\
\hline t statistics & -2.115 & $\begin{array}{l}\text { p- } \\
\text { value: }\end{array}$ & 0.036 & & & & & \\
\hline
\end{tabular}




\begin{tabular}{|l|l|l|l|l|l|l|}
\hline High-Low & 0.171 & 0.264 & 0.244 & 0.140 & 0.221 & 0.111 \\
\hline t statistics & $\mathbf{- 2 . 9 1 8}$ & $\begin{array}{l}\text { p- } \\
\text { value: }\end{array}$ & $\mathbf{0 . 0 0 5}$ & & & \\
\hline
\end{tabular}

Source: Wharton Research Data Services (WRDS): Compustat North America Fundamentals Annual.

Table 7 represents the means of the MA_RET, the number of observations (N) as well as the portion of the positive MA_RET that was found for each F_SCORE value (1-9). Most of the observations are clustered around F_SCORES with values equal to four to six (4-6). The mean of MA_RET of all companies' observations $(\mathrm{N}=230)$ within the period under examination (2011-2014), is negative and equal to 0.2. This it is attributed to the poor financial performance of high BM companies that comprise the entire sample.

For the group of high performing companies (with F-score higher than 7) the mean of MA_RET equals to $-0.129(\mathrm{~N}=34)$ and for low performing companies (with Fscore lower than 4), the mean of MA_RET equals to $-0.300(\mathrm{~N}=144)$. The findings show that by choosing the high performing companies to form the portfolio, the latter minimizes the losses that exhibiting the high BM companies for the specific period under examination. In particular, the high performing companies show the least negative return (-0.129) among all companies that achieve collectively considerable losses to the tune of -0.20 on the average. Therefore, the difference in the means between high and all companies' observations is equal to 0.071.Significantly, the mean of MA_RET earned by a high BM-portfolio can be increased by at least $7.1 \%$ annually, through the selection of high performing companies. The findings are in line with Piotroski's claims that the mean returns earned by a high BM-portfolio, is bolstered annually through the inclusion of high performing companies, based on the F-score screening mechanism. The specific portfolio of stocks chosen minimizes the losses of the entire high BM companies group.

Using the t-test, we compare the mean return of high performing companies and all others. According to the results the t-statistic $=-2.115$ and the p-value $=0.036<$ 0.05. Therefore, we have to reject the hypothesis that the mean return of high performing companies is the same as the mean return of all others companies. High performing companies exhibit a greater mean of MA_RET that is equal to 0.072.

Using the t-test, we compare the mean return of high performing companies and low performing companies. According to the results, the t-statistics $=-2.918$ and the $\mathrm{p}$ value $=0.005<0.05$. Therefore, I have to reject the hypothesis that the mean return of high performing companies is the same as the mean return of low performing companies. High performing companies exhibit a greater mean of MA_RET that is equal to 0.171 
Then, we repeat the recalculation of the previous table using as dependent variable RAW_RET, instead of MA_RET.

Table 8: Raw Returns by F-score groups

\begin{tabular}{|l|l|l|l|l|l|l|l|l|}
\hline RAW_RET & $\begin{array}{l}\text { Mean of } \\
\text { Raw_RET }\end{array}$ & $\mathbf{5 \%}$ & $\mathbf{2 5 \%}$ & $\mathbf{5 0 \%}$ & $\mathbf{7 5 \%}$ & $\mathbf{9 5 \%}$ & $\mathbf{N}$ & $\begin{array}{l}\text { n\% } \\
\text { positive }\end{array}$ \\
\hline F_SCORE= 1 & -0.045 & -0.079 & -0.079 & -0.045 & -0.011 & -0.011 & 2 & $0.00 \%$ \\
F_SCORE= 2 & -0.144 & -0.632 & -0.284 & -0.111 & -0.065 & 0.203 & 9 & $0.22 \%$ \\
F_SCORE= 3 & -0.222 & -0.668 & -0.443 & -0.228 & 0.015 & 0.126 & 23 & $0.26 \%$ \\
F_SCORE= 4 & -0.110 & -0.639 & -0.392 & -0.024 & 0.113 & 0.317 & 55 & $0.44 \%$ \\
F_SCORE= 5 & -0.079 & -0.696 & -0.258 & -0.026 & 0.184 & 0.344 & 53 & $0.42 \%$ \\
F_SCORE= 6 & -0.123 & -0.774 & -0.220 & -0.088 & 0.041 & 0.220 & 36 & $0.39 \%$ \\
F_SCORE= 7 & 0.009 & -0.559 & -0.153 & -0.022 & 0.176 & 0.654 & 36 & $0.47 \%$ \\
F_SCORE= 8 & -0.022 & -0.613 & -0.216 & -0.052 & 0.285 & 0.492 & 14 & $0.43 \%$ \\
F_SCORE= 9 & -0.095 & -0.176 & -0.176 & -0.095 & -0.014 & -0.014 & 2 & $0.00 \%$ \\
\hline \hline All Firms & -0.093 & -0.636 & -0.273 & -0.063 & 0.125 & 0.361 & 230 & $0.40 \%$ \\
\hline \hline Low & -0.191 & -0.668 & -0.348 & -0.156 & -0.011 & 0.203 & 34 & $0.24 \%$ \\
\hline Medium & -0.102 & -0.659 & -0.317 & -0.055 & 0.128 & 0.273 & 144 & $0.42 \%$ \\
\hline High & -0.004 & -0.559 & -0.178 & -0.025 & 0.176 & 0.492 & 52 & $0.44 \%$ \\
\hline \hline High-All & 0.089 & 0.077 & 0.096 & 0.038 & 0.051 & 0.131 & & \\
\hline t statistics & 2.456 & $\mathbf{p}-$ & 0.015 & & & & & \\
\hline \hline High-Low & 0.187 & 0.109 & 0.171 & 0.131 & 0.187 & 0.289 & & \\
\hline t statistics & -2.970 & $\mathbf{p}-$ & 0.004 & & & & & \\
\hline Source: & value: & & & & & & & \\
\hline
\end{tabular}

Source: Wharton Research Data Services (WRDS): Compustat North America Fundamentals Annual.

According to the findings exposed in the table above not only the market-adjusted stock returns (MA_RET), but also the raw ones (RAW_RET) exhibit similar behavior with respect to the F_SCORE. The high performing group exhibits mean of RAW_RET that is equal to -0.004. The latter reveals that the mean of RAW_RET for high performing group is higher compared to the means of medium and low performing groups, which are equal to $-0,102$ and -0.191 respectively. The mean 
differences are statistically significant, since the $\mathbf{t}$ test values are 2.456 and -2.970 and the corresponding p-values 0.015 and 0.004 at the $5 \%$ level.

Given the above results, it is obvious that the F-score screening apparatus that segregates high and low performing companies' observations, contributes to the creation of a portfolio that improves the mean of returns. Therefore, we can accept the main hypothesis of my research states that "the one-year ahead change of stocks' market-adjusted returns (MA_RET) and raw returns (RAW_RET), is at high financial performing companies higher than that of lower performing companies'.

\section{Conclusion}

The F score model challenges the semi strong form of efficient market hypothesis (EMH) according to which all publicly available relevant information is already embedded in the stock prices and therefore investors are not able to achieve returns that outpeform the market. The model defies the view that there is no way for someone to "beat" the markets, since all the investors face the same information set and financial statements' data are already available to the public. The F-score mechanism represents a rewarding investment strategy for the practitioners, if it is properly applied. It also contributes to more efficient allocation of resources in the economy, by directing resources to companies that expose more sound fundamentals.

\section{References:}

Altman, E., 1968. Financial Ratios, Discriminant Analysis and the Prediction of Corporate Bankruptcy. Journal of Finance, September.

Abarbanell, J. and Bushee, B. 1998. Abnormal returns to a fundamental analysis strategy. The Accounting Review, 73, 19-45.

Ball, R. and Brown, P. 1968. An empirical evaluation of accounting income numbers. Journal of Accounting Research, 6, 159-178.

Beaver, W. 1968. The information content of annual earnings announcements. Journal of Accounting Research, Supplement, 67-92.

Chen, N.F. and Zhang, F. 1998. Risk and return of value stocks. The Journal of Business, 71(4), 501-535.

Dechow, P. 1994. Accounting Earnings and Cash Flows as Measures of Firm Performance: The Role of Accounting Accruals. Journal of Accounting and Economics, 18, 3-42.

Dechow, P. and Dichev, I. 2002. The quality of accruals and earnings: The role of accrual estimation errors. The Accounting Review, 77, 35-39.

Dechow, P., Sloan, R. and Zha, J. 2014. Stock Prices \& Earnings: A History of Research.

Fama, E.F. 1965. The behavior of stock market prices. Journal of Business, 38, 34-105.

Fama, E.F., French, K.R. 1992. The Cross-Section of Expected Returns. Journal of Finance, 47, 427-465.

Fama, E.F., French, K.R. 1995. Size and book-to-market factors in earnings and returns. The Journal of Finance, 50(1), 131-155.

Fama, E.F., French, K.R. 2008. Dissecting anomalies. The Journal of Finance, 63. 16531678. 
Field, A. 2009. Discovering statistics using SPSS (3nd ed.). London: Sage.

Hanias, P.M., Curtis, G.P. and Thalassinos, E.J. 2007. Non-linear dynamics and chaos: The case of the price indicator at the Athens Stock Exchange. International Research Journal of Finance and Economics, 11(1), 154-163.

Harris, M., Raviv, A. 1990. Capital structure and the informational role of debt. The Journal of Finance, 45(2), 321-349.

Kothari, S.P. 2001. Capital markets research in accounting. Journal of Accounting and Economics, 31, 105-231.

Kousenidis, D.V., Ladas, A.C. and Negakis, C.I. 2013. The effects of the European debt crisis on earnings quality. International Review of Financial Analysis, 30, 351-362.

Krauss, Ch., Krüger, T., Beerstecher, D. 2015. The Piotroski F-Score: A fundamental value strategy revisited from an investor's perspective. IWQW Discussion Paper Series, 13.

Lakonishok, J., Shleifer, A. and Vishny, R. 1994. Contrarian investment, extrapolation, and risk. Journal of Finance, 49, 1541-1578.

Miller, M.H., Rock, K. 1985. Dividend policy under asymmetric information. The Journal of finance, 40(4), 1031-1051.

Myers, S.C., Majluf, N.S. 1984. Corporate financing and investment decisions when companies have information that investors do not have. Journal of financial economics, 13(2), 187-221.

$\mathrm{Ou}, \mathrm{J}$. and S. Penman, S. 1989. Financial statement analysis and the prediction of stock returns. Journal of Accounting and Economics, 11, 295-329.

Piotroski, J. 2000. Value investing: The use of historical financial statement information to separate winners from losers. Journal of Accounting Research 38 (Supplement), 141.

Porter, M.E. 1980. Competitive Strategy. Free Press.

Thalassinos, I.E., Thalassinos, E.P. 2006. Stock Markets' Integration Analysis. European Research Studies Journal, 9(3-4), 3-14.

Thalassinos, I.E. and Politis, D.E. 2011. International Stock Markets: A Co-integration Analysis. European Research Studies Journal, 14(4), 113-129.

Thalassinos, I.E., Hanias, P.M. and Curtis, G.P. 2012. Time series prediction with neural networks for the Athens Stock Exchange indicator. European Research Studies Journal, 15(2), 23-31.

Thalassinos, I.E., Stamatopoulos, D.T. and Thalassinos, E.P. 2015. The European Sovereign Debt Crisis and the Role of Credit Swaps. Chapter book in The WSPC Handbook of Futures Markets (eds) W. T. Ziemba and A.G. Malliaris, in memory of Late Milton Miller (Nobel 1990) World Scientific Handbook in Financial Economic Series Vol. 5, Chapter 20, pp. 605-639, ISBN: 978-981-4566-91-9, (doi: 10.1142/9789814566926_0020). 